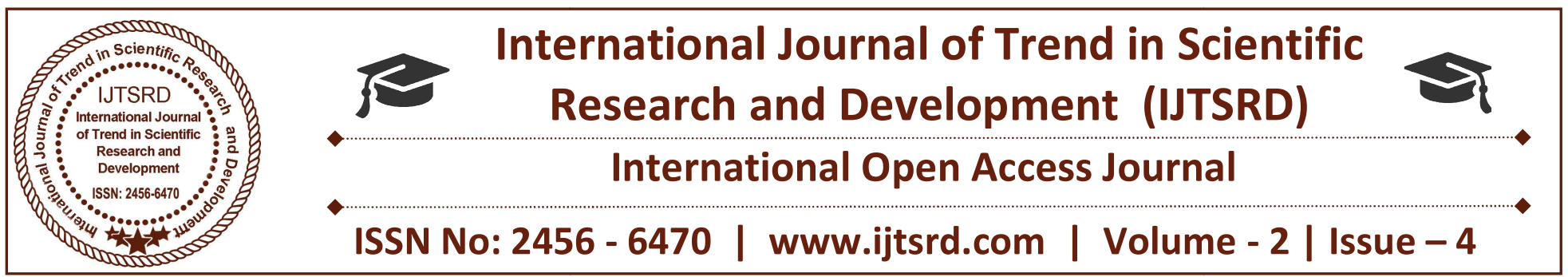

\title{
Awareness of Mothers Towards Breast Feeding in Allahabad City
}

\author{
Sangita Srivastava, Jyotshna Singh \\ Home Science Department, Nehru Gram Bharti Vishvidhaylya, Jhunsi, \\ Allahabad, Uttar Pradesh, India
}

\begin{abstract}
Breast feeding an ideal food for infants, it has been found beneficial not only to the infants but also to the mothers. Mother milk is complete food for infants its provides nourishment for the first six months of infant's life. It provides all the essential nutrients for infant's growth and development. Breast feeding is an unequalled way of providing ideal food for the healthy growth and development of infants, it is also an integral part of the reproductive process with important implications for the health of mothers. In this paper we proposed a study awareness of mother and her infant's urban area of Allahabad City. In this study we discovered and discussed awareness of mothers how to responsible to feeding pattern of infants growth and development age of 0-12 months. The questionnaire based survey of mothers and her infants aged 0-12 months was conducted in 200 mothers. Our proposed study shown that $97.5 \%$ mothers were aware about the breast feed practices and other are not feed due to illness of mother and some other reason, so they are not given breast feed to their infants. $91 \%$ mothers are aware to given colostrums because it is the first preventive mother milk for infants.
\end{abstract}

Keywords: Infants, breast feeding, awareness, health, infants growth, Colostrum

\section{INTRODUCTION}

Breast milk is the essential nutrients that an according to infant needs in the first six months of life [1]. It has the first communication way between the mother and infant. Previous studies have shown that breast feeding has advantages for both. Mother milk provides essential nutrition for the babies, boosts the immune system [2]. It improves the figure of the mother and reduces the risk of Cancer of breast and
Ovary. Previous studies have shown babies who were breast-fed had a higher I.Q. then those babies who were given others forms of milk [3]. World Health Organization recommended breast feeding as a main source of food for babies for the first six months and encourage mother to consider breast feeding as the only feeding source. Babies aged between 6 months and 2 years, it was recommended [2]. The survey on Children Ministry of Women and Child Development 2015 shows that only $45 \%$ infants are now being breast feed within an hour of birth in India, and just $65 \%$ are being exclusively breast feed as per W.H.O. recommendation [4]. In Uttar Pradesh breast feeding practices which are not up to the mark only $39.4 \%$ of new born receive breast milk within one hour and about $20.8 \%$ infants sustain mother milk till 35 weeks (Annual health survey 2012-13) [5]. First food which given to the new born child are known as Prelacteal foods, which are the most common prelactal feed in India is honey, boiled water, glucose water, sugar water and dilute milk[6]. Colostrum which has also been called the first milk "liquid gold" or "immune milk" is a clear sticky, thick liquid that is produced by a mother's mammary glands after the first day of her babies birth [7]. One day one, babies stomach capacity is about $5-7 \mathrm{ml}$, or the size of marble. This is the why just a few tsp of colostrum is needed to satisfied a baby's appetite. [8]. Colostrum is the first breast milk produced after birth and is important for promotion of health and prevention of infections of the new born immediately after birth [7]. When a mother has no confidence to stop breast feeding regardless of her infant's age and then she started complimentary feeding it is defined as the process starting when breast milk alone is no longer sufficient to meet the natural requirements of infants, and therefore other foods and liquids are needed along 
with breast milk[9]. Joan Mukibi Namakula, a midwife at International Hospital, Kampala says that if mothers do not wash their breast and nipple properly, they expose their babies to various diseases and infections, it is because "a dirty breast harbors germs and when infant suckles a high chances that they will get sick."[10]. In the State of U.P. in Lucknow three out of five mothers in the state could be starving their babies because $60 \%$ mothers in U.P. do not breast feed them exclusively for the recommended six months.[11].

\section{MATERIALANDMETHOD}

This cross sectional study was conducted on 200 mothers of infants aged 0-12 months in Allahabad city. All mothers selected at the age of 20-40 years subjects were explained orally about the study. The main purpose of this study to aware of feeding practices and hygiene of breast feeding and improve health and development through infant feeding practices. In questionnaires includes various factors that have potential effect on breast feeding practices and various demographic and socioeconomic factors like age, education, profession, religion regarding initiation and duration of breast feeding importance of Colostrum, cleaning of breast before and after feeding and time of weaning practices of infants etc.

\section{RESULT}

Total of 200 mothers participated and out of 200 mothers, 30\% mothers are aged between 30-35 years, $26 \%$ mothers are $20-25$ years, $21 \% 30$ - 40 years and it found that the maximum awareness are in the age group of 30-35 years. Maximum mothers are aware about to breast feed. $97.5 \%$ mothers are given her milk but due to some reason $2.5 \%$ mothers are not given her milk. As Shown in Figure

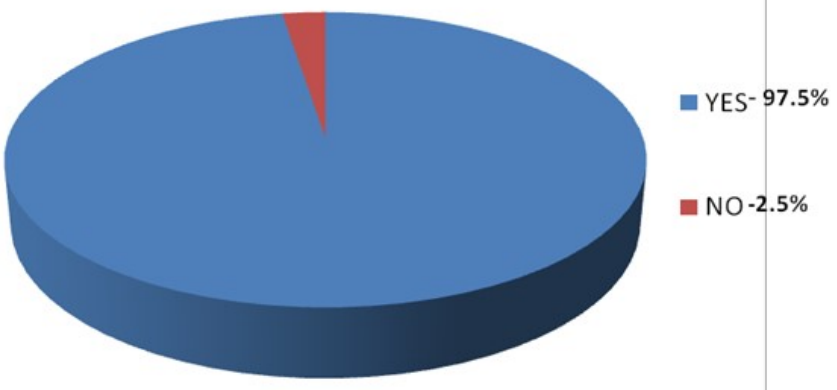

Figure No. 1

The distribution of infants according to colostrums given are not. Maximum 91\% infants were given Colostrum and 9\% mothers are not given. As shown in Figure

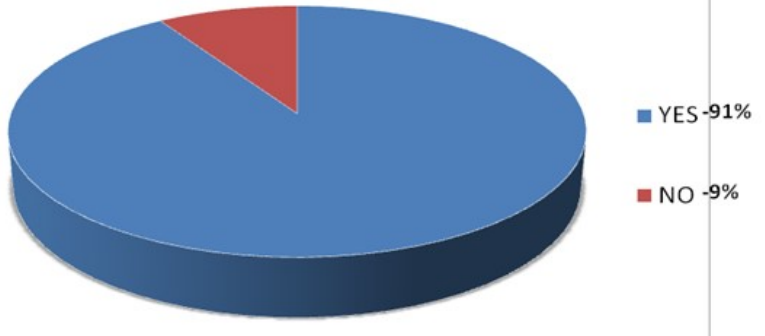

Figure No. 2

It is evident that $54 \%$ mothers clean her breast before feeding and rest mothers are some time or not clean due to without proper knowledge of hygiene. As shown in Figure

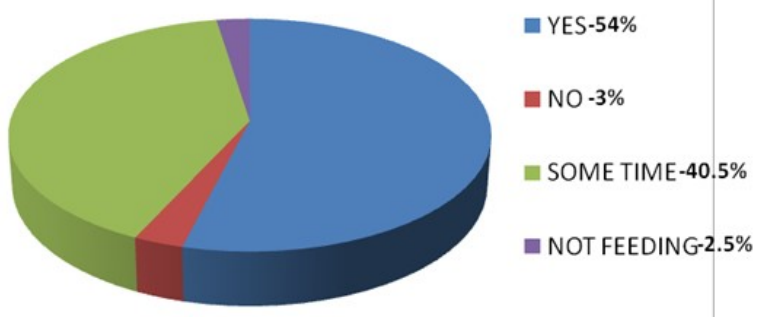

Figure No. 3

Distribution of infants according to the period of given only breast milk majority of the mothers $38 \%$ are given her milk 3 to 6 months, 32\% mothers are given 0 to 3 months, $20.5 \%$ mothers feed her milk 6 to 9 months and $7 \%$ only given 9 to 12 months and due to some causes $2.5 \%$ are fed mother milk. As shown in Figure

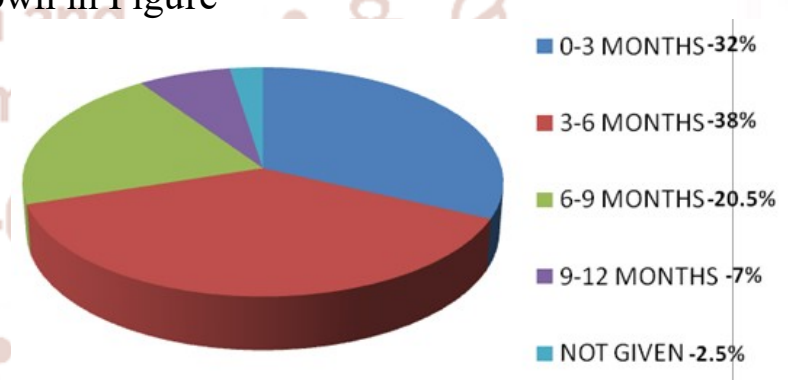

\section{DISCUSSION}

Figure No. 4

Breast milk is the natural food for infants, which is the first food for infant. It's provides all type boost of energy and nutrients that the baby need for starting month of life and continued to provide up to half are more of a Childs nutritional need during the second half of their first year and up to one third during the second year of life. Breast milk promotes sensory and cognitive development and protects the infant against infectious and chronic diseases. Exclusively breast feeding reduces infant mortality due to common childhood illness such as Diarrhea or Pneumonia and helps for a quicker recovery during illness. In present study maximum mothers (97\%) are aware towards breast feeding of infants, behind the reason, that Allahabad is a educational hub so the maximum mothers are educated (According to our study $80.5 \%$ 
mothers are educated more then $10^{\text {th }}$ class and only $6 \%$ are illiterate) so they know the advantage of breast feeding. According to "UNICEF" mother milk is the ideal nourishment for infants for their first six months of life that provides all nutrients including Vitamins and minerals. In our study only $38 \%$ mothers are given only breast milk to their infants. National Family Health Survey (NFHS-4) report shows that only $41 \%$ babies in the State of U.P. were breast fed exclusively for six weeks, the result is not satisfactory because according to doctors advise only mother milk is necessary to the infants of 0 to 6 months.

In our study 54\% mothers are aware about the knowledge of hygiene so they used to clean her breast before and after feeding the rest mothers are not aware about the dirty breast harbors germs and when an infant suckles it they effected form it.

The result of survey is not satisfactory in the eye of researcher because the result shows that only $20.5 \%$ mothers are given her child 6 to 9 month and only $7 \%$ mothers are given 9 to 12 months so she is trying to improved the result with her own efforts. The nature gives the best gift to the infants through the breast feeding but unfortunately in our country (Allahabad Urban area also) it can not be provided them properly as result shows due to lack of unawareness of the not only mothers but also society too that very reason after a lot of efforts we could not find a satisfactory result.

\section{CONCLUSION}

Breast feeding contribute to the health wealth, being of mothers, it helps to space children reduces the risk of ovarian cancers and breast cancers, increases family and national resources, is a secure way of feeding and is safe for the environment. Mother milk is called natural immunization for children. Infants who get mothers milk soon after birth, they are high level of emotional and mentally fit. In the society of India many mothers and their relatives are not known about the first milk Colostrum, Colostrum is the first milk that a breast feeding naturally produces in the weeks before delivery and in the early days of breast feeding, it is like liquid gold of the children for whole life, so the aim of our study to done the best interest of child and to insure to best possible start to life to every babies as foundation for full filament of every child's right to survival growth, development, protection and participation without discrimination. National Health Mission, which has planed a number of activities to spread awareness about the cause over the week under Union Health Ministry's special program MAA (mothers absolute affection). Breast feeding is an important topic in health education because of the many benefits that can be gained for babies, mothers and communities for example, the components of breast milk provide the needed nutrition for babies and boost the baby's immune system. Also, practicing breast feeding helps mothers lose weight after pregnancy and stimulates the uterus to return to its previous position before pregnancy (the office on women's health, 2012). The researcher is interested in improve the awareness toward breast feeding in Allahabad City. Breast feeding knowledge practices and attitudes were investigated to identified the factors that will encourage breast feeding.

\section{REFERENCE:-}

1. Meseret Ekubay, Aster Berhe and Engid a Yisma "initiation of breast feeding with one hour of birth among mothers with Infants younger then or equal to six months of age attending public health institutions in Addis Ababa Ethiopia" In journal of International breast feeding journal, 2018 https://doi.org/10.1186/S1 3006-018-0146-0

2. Breast feeding knowledge, practice, attitudes and influencing factors endings from a selected sample of breast feeding mothers in Bemidji Minnesota Hadeel Adnan Tanash Minnesota State University Mankato 2014 Corner stone.

3. GHAI OP "Essential Pediatrics fourth edition Mehat Publishers PP-126-127.

4. WWW.Searo.Who.int/india/topics/nutrican breast feeding/en/

5. Knowledge and practice off exclusive breast feeding among women in rural Uttar Pradesh Verma Akansha and Dixsit Priyanka

6. Breast feeding practices in infants of rural Weston Uttar Pradesh reason of India Kumar D, Singh Mv, Sharma IK, Shukal KM, Varshney S PP- 629.

7. Colostrum feeding practices and its determinants among Urban and rural mothers in Kamroop Assam India IJRMS Rana Kakati, Syada Jesmin Rahman, Madhur Borah, Hiyeswar Borah Vol 4, No.10 (2016) > Kakati

DOI: http://dx.doi.org/10.18203/2320-

6012.ijrms20163331 
International Journal of Trend in Scientific Research and Development (IJTSRD) ISSN: 2456-6470

8. Colostrum benefits for baby-Breast feeding- 10. "33L infants in Uttar Pradesh Stave as mothers Problems.com

https://www.breastfeedingproblems.com don't breast feed" Shailvee sharda ! TNN ! updated; Aug!,2017

9. Guiding principals for Complementary feeding of the breast fed Child PAN AMERICIAN HEALTH ORGANIZATION WORLD HEALTH

11. How to maintain good hygiene when breast feeding Daily Monitor Monday January 132014 www.monitor.co.ug

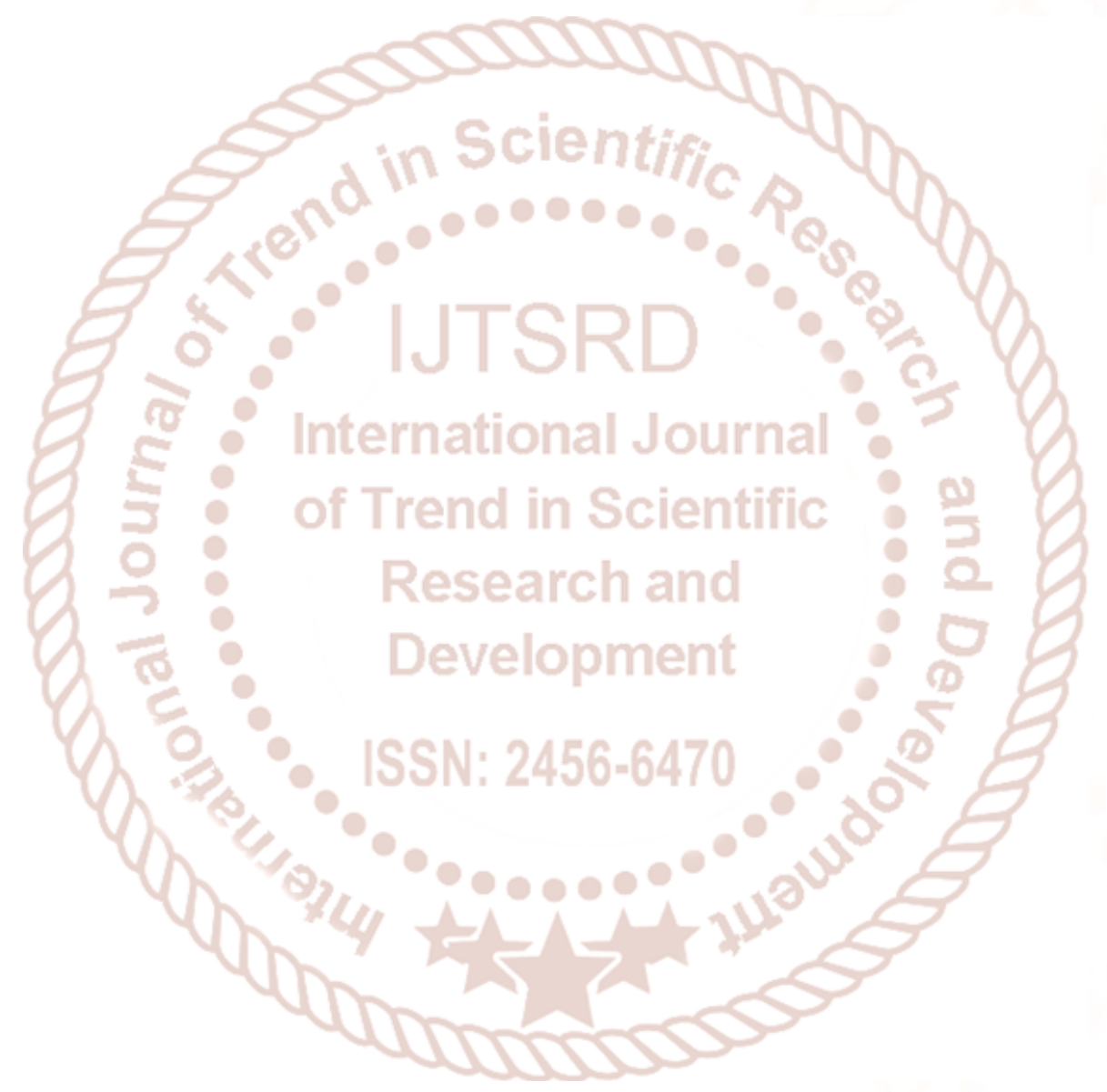

